\title{
Use of "tent-pole" graft for setting columella-lip angle in rhinoplasty
}

\author{
Kapil Agrawal, Raghav Shrotriya \\ Department of Plastic Surgery, KEM Hospital, Mumbai 400012, India. \\ Correspondence to: Dr. Raghav Shrotriya, Department of Plastic Surgery, KEM Hospital, Gynec. Wing, 2nd Floor, Parel, Mumbai \\ 400012, India. E-mail: dr.raghav.s@gmail.com
}

How to cite this article: Agrawal K, Shrotriya R. Use of "tent-pole" graft for setting columella-lip angle in rhinoplasty. Plast Aesthet Res 2018;5:13. http://dx.doi.org/10.20517/2347-9264.2018.17

Received: 26 Mar 2018 Accepted: 26 Mar 2018 Published: 18 Apr 2018

Science Editor: Raúl González-García Copy Editor: Jun-Yao Li Production Editor: Cai-Hong Wang

Sir,

In patients of rhinoplasty, columella-labial angle (CLA) is an important parameter to be evaluated if a pleasant aesthetic result is desired. An increase in this angle results in an upward tilt of the base of the nose with a concomitant decrease in nasal length. Owing to the wide anatomic variability, it is often times missed, thereby leading to sub-optimal surgical results.

The relationship between the columella and upper lip is complex. Trying to maintain a particular angle in patients of rhinoplasty is difficult and entails use of various manoeuvres like suturing techniques, cartilage grafts and nasal cartilage modifications. The caudal septum, nasal spine and medial crura of the lower lateral cartilages help shape the columella and thus contribute to the determination of the CLA ${ }^{[1]}$. On profile view, the desired columella-labial angle is $95^{\circ}$ to $100^{\circ}$ in men and $100^{\circ}$ to $110^{\circ}$ in women ${ }^{[2]}$. The normal columellar show ranges from 2 to $4 \mathrm{~mm}$. A long or hanging columella can significantly disturb the aesthetic effect of the nose. Here the authors describe 'the tent pole graft', an innovative technique used to set and maintain the columellar lip angle.

The "tent-pole graft" works in a manner similar to the septo-columellar interpositional grafts but here there is no need to dissect or separate upper lateral cartilages from septum to fix the grafts. This graft is akin to fixing a bamboo of a tent in position. It is used in difficult secondary noses and cases where tip projection is increased significantly by putting long columellar strut, which tends to fall back (as in Binder's syndrome).

In this technique, a piece of cartilage is fixed to columellar strut in a desired position and then the optimal angle is chosen by fixing the posterior end of graft temporarily with a needle to supratip cartilaginous

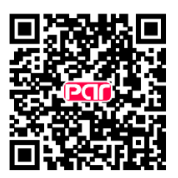




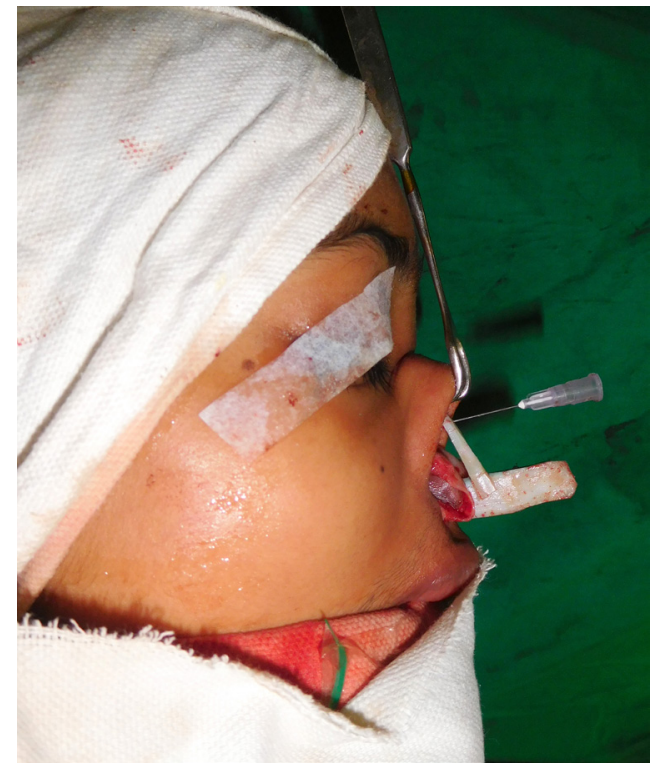

Figure 1. Picture in lateral view of a patient who underwent rhinoplasty, showing temporary fixation of the tent pole graft to set the columella labial angle using needle

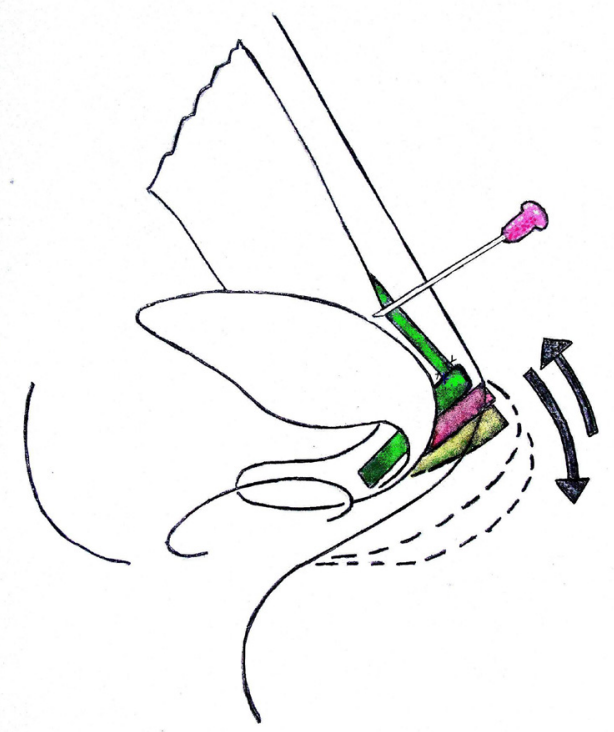

Figure 2. Schematic diagram corresponding to Figure 1, showing temporary cartilage graft fixation using needle so that it can be increased or decreased easily by sliding

dorsum [Figures 1 and 2]. Once sure of the angle, the graft is sutured to the dorsum [Figures 3 and 4]. Tent pole graft keeps long columellar strut stable and doesn't allow the tip to fall back. It not only helps in maintaining but gives a liberty to create a CLA of choice. Authors usually use it whenever tip support is needed in secondary rhinoplasties and cases where lengthening of tip or columella is done, to maintain the desired columellar-labial angle, and to maintain the nasal length in patients with short noses. This graft can be moved serially to easily adjust the nasolabial or columella-labial angle. To avoid supratip show of the graft the dorsal limb of the graft is placed and fixed to columellar strut 3-4 mm lower than the actual tip height. The tent pole graft is a variant of L-strut. An L-strut can be used to serve the same purpose of creating and maintaining a CLA of choice, but tent pole graft, which is fixed in supratip region, provides the liberty to 


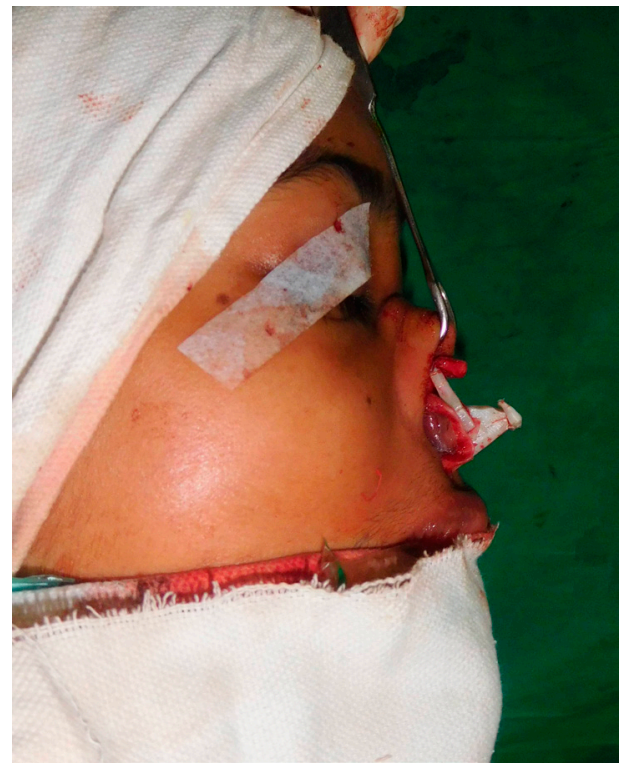

Figure 3. Picture in lateral view. Once the required columella labial angle is set, the tent pole graft is sutured to the dorsum to fix it

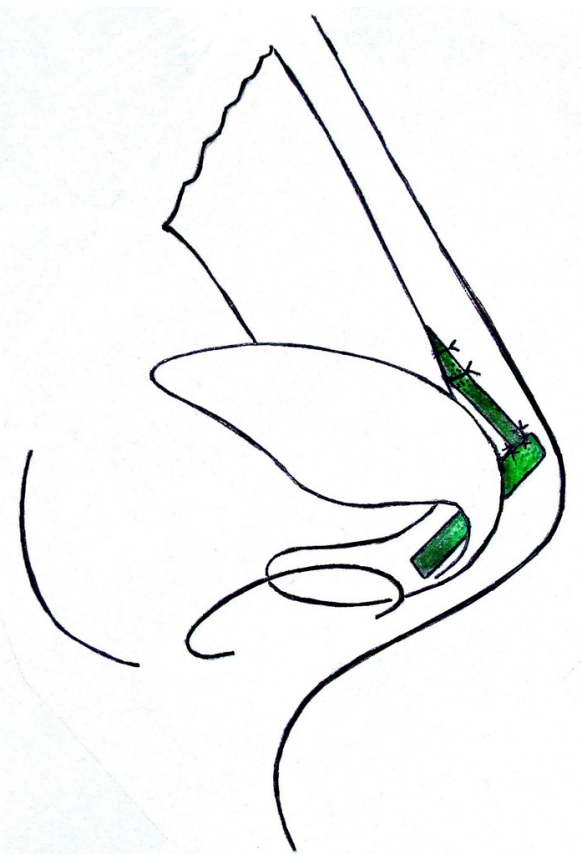

Figure 4. Schematic diagram corresponding to Figure 3, showing final suturing of the cartilage graft to the dorsum once the angle is set

design a natural and soft looking dorsum. The authors have used this technique in more than 25 patients of rhinoplasty with satisfactory results. A representative case is shown in Figure 5.

Based on various modifications of lateral crural cartilages, Webster et al. ${ }^{[3]}$ were the first to describe options for tip rotation. Ozmen et al. ${ }^{[4]}$ described the sliding alar cartilage technique for nasal tip modification in which lower lateral cartilage is used. Bohluli et al. ${ }^{[5]}$ have described lateral crural anchorage flaps in which excessive parts of the lateral crural cartilages are used as anchorage flaps and fixed with needle to the septum to set the nasal tip position. Honrado and Pearlman ${ }^{[1]}$ have reviewed in detail various techniques for adjustment of naso-labial angle in rhinoplasty. 

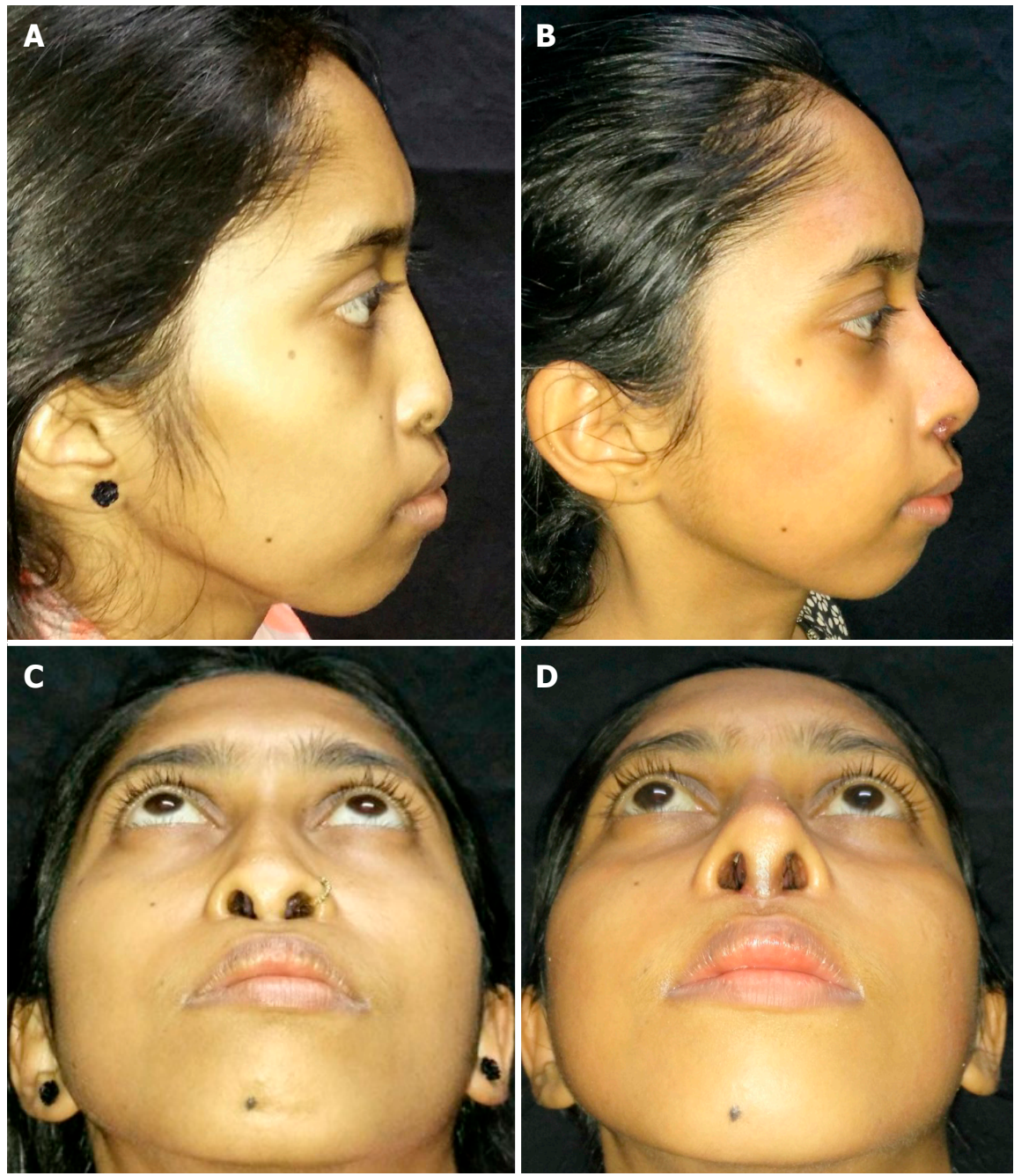

Figure 5. Clinical photograph of a patient who underwent cosmetic rhinoplasty for Binder's Syndrome. (A) Preoperative photograph lateral view; (B) postoperative photograph after the use of "tent pole" graft, lateral view; (C) preoperative photograph, basal view; (D) postoperative photograph after the use of "tent pole" graft, basal view

Indian noses have peculiar combination of thick skin and weak alar cartilages. Tip refinement by suturing technique is possible only in select cases. Most of the Indian noses and especially secondary noses need add on grafts to build and refine the tip. The major techniques used to rotate the tip caudally, are septal extension graft, a columellar strut supported with extended spreader grafts and structured columellar strut. Both caudal septal extension and extended spreader grafts are the techniques of choice when either septal work is needed or in a severely short nose.

Tent pole graft is particularly helpful in cases where septal extension graft is either not feasible or very difficult to put, e.g., Binders, mild to moderate short nose, secondary noses. In cases where the noses need augmentation and tip pasty, the tent pole graft comes as a useful tool for rhinoplasty surgeons to provide mild to moderate increase in the length of nose without the need of dissection and septal extension graft, to support columellar strut and to set and maintain nasolabial angle. Thus, the "tent pole graft" technique may be used in difficult secondary nasal tip, cleft lip rhinoplasty and in noses with depressed tip (Binder's Syndrome) to prop the columella strut graft and provide optimal results to tip modification in patients undergoing rhinoplasty. 


\section{DECLARATIONS}

\section{Authors' contributions}

Concept, design, definition of intellectual content, clinical studies, data acquisition, manuscript preparation, manuscript editing, and manuscript review: Agrawal K

Literature search, data acquisition, data analysis, statistical analysis, manuscript preparation: Shrotriya $\mathrm{R}$

Financial support and sponsorship

None.

\section{Conflicts of interest}

There are no conflicts of interest.

\section{Patient consent}

Consent has been taken.

\section{Ethics approval}

Not applicable.

\section{Copyright}

(c) The Author(s) 2018.

\section{REFERENCES}

1. Honrado CP, Pearlman SJ. Surgical treatment of the nasolabial angle in balanced rhinoplasty. Arch Facial Plast Surg 2003;5:338-44.

2. Sherris DA, Kern EB. Computer-assisted facial analysis. In: Cummings C, Krause CJ, editors. Otolaryngology Head \& Neck Surgery. Vol 2. St Louis, Mo: Mosby-Year Book Inc; 1998. p. 833-43.

3. Webster RC, Davidson TM, Smith RC. Importance of the columellar-labial junction in rhinoplasty. Head Neck Surg 1979;1:423-34.

4. Ozmen S, Eryilmaz T, Sencan A, Cukurluoglu O, Uygur S, Ayhan S, Atabay K. Sliding alar cartilage (SAC) flap: a new technique for nasal tip surgery. Ann Plast Surg 2009;63:480-5.

5. Bohluli B, Varedi P, Nazari S, Bagheri SC. Lateral crural suspension flap: a novel technique to modify and stabilize the nasolabial angle. J Oral Maxillofac Surg 2013;71:1572-6. 